\title{
A FUNÇÃO TELEOLÓGICA DO FANTÁSTICO EM COMO OS PÁSSAROS DESPERTAM O SOL
}

\author{
Sigrid Renaux*
}

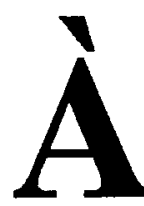

primeira vista, o conto Como os Pássaros Despertam o Sol inicia uma narrativa mítica, um "era uma vez", no qual o narrador resgata a história de cinco gerações de sua familia. Entretanto, essas histórias e tradições passadas aos poucos vão se concentrando na pessoa do narrador, deste modo confirmando e acentuando as estranhas coincidências que percorrem a tradição familiar e que levam ao desenlace. Nosso objetivo será percorrer as diversas etapas desta narrativa, fazendo uma leitura de suas categorias ficcionais ou microestruturas, a fim de melhor captar a força e a transcendência que o fantástico vai adquirindo na contextura semântica ou macroestrutura do conto até atingir o próprio narrador, num "aqui e agora" que por sua vez já estava latente no início do processo diegético.

O conto está nitidamente dividido em duas partes: a primeira, no passado, recapturando os acontecimentos relacionados com o tetravô do narrador e sua cachorra; em seguida, como a cachorra e seus filhotes eram vistos pelos

* Universidade Federal do Paraná.

1 MACLEOD, Alistair. 'As Birds Bring Forth the Sun'. In: BESNER, N. ; STAINES , D. eds. The Short Story in English. Tradução de Sigrid Renaux. Toronto : Oxford University Press, 1991. p. 708-14. 
descendentes do tetravô, sempre em relação com a morte deles. A segunda parte, no presente, na qual o narrador em companhia de seus cinco irmãos cercam o leito do pai moribundo num hospital em Montreal, ao mesmo tempo aguardando, temerosos, a chegada inevitável do espectro familiar.

Concentrando-nos inicialmente na parte mítica do conto - que ocupa enfaticamente 5 das 6 páginas do total, percebemos que ele se inicia com aquela indeterminação temporal tão comum nos contos de fadas: "Era uma vez uma familia com sobrenome da Alta Escócia que morava perto do mar".2 Esta indeterminação temporal, entretanto, adquire uma referencialidade atmosférica ao se situar as diversas etapas da história do homem e sua cachorra sempre inseridas nas mudanças das estações do ano, traduzindo uma preocupação em transmitir o relato de épocas passadas através dos ciclos da natureza, já que as ocupações da família, como pescaria e plantio, estão evidentemente subordinadas às estações do ano: o atropelamento da cachorra ocorre em outubro, na época chuvosa de outono; sua convalescença durante o outono e começo do inverno; na primavera seguinte, ela acompanha o homem por toda parte; no primeiro cio, o homem a cruza com outro cachorro; no inverno seguinte ela está prenhe; desaparece nuına manhã de quase primavera; a família espera em vão por ela durante o verão, outono e inverno; no verão seguinte, dá-se o reencontro do homein com a cachorra numa ilha, seguido de sua morte, estraçalhado pelos filhotes dela.

É neste momento que acontece a única referência cronológica exata desta parte da narrativa, quando o narrador diz: "Tudo durou talvez um pouco mais de um minuto", ${ }^{3}$ deste modo enfatizando a incrível rapidez desse momento chocante de rcencontro e morte, contrastando ainda mais com o lento passar das estações do ano do início da narrativa. É apenas após esse incidente que são feitas referências concretas ao tempo cronológico, como "um grupo de homens vai até a ilha algumas semanas" ${ }^{4}$ após o acontecimento, vão novamente à ilha "um ano depois", 5 dando assim um toque realista à procura da cachorra e dos filhotes. E a primcira parte da narrativa mítica se encerra com o narrador dizendo que "tudo isso aconteceu bá muito, muito tempo", 6 o que completa o círculo da história que se havia inciado com "era uma vez".

Se a indeterminação temporal inicial e final, bem como a determinação temporal do interior desta parte da narrativa já nos abrem espaço para uma dupla referencialidade, há entretanto já dentro do espaço temporal um indício que irá

\footnotetext{
2 "Once there was a family with a Highland name who lived beside the sea".

"It all took perphaps little more than a minute."

"After some weeks, a group of men circled the island."

"a year later."

"all of this happened a long, long time ago."
} 
levar ao fantástico: a descrição da cachorra como um "cão veadeiro vindo de outras eras", 7 isto é, de uma época não apenas anterior à entrada da cachorra na história familiar, mas ainda anterior ao "era uma vez" e portanto não apenas indeterminada, mas com conotações míticas, de tempos quase primordiais, nos quais existiam monstros e animais fabulosos. Portanto, temos uma moldura temporal com a história da família e dentro dela outra paralela, com a história da cachorra, mas que ao mesmo tempo irá romper a moldura inicial através do elemento fantástico "de outras eras", que precede o "era uma vez".

Esta dupla referencialidade do espaço temporal torna-se também aparente no espaço cênico. A narrativa se inicia com a imprecisão do local onde morava esta família, pois apesar de seu sobrenome ser oriundo da regiäo montanhosa da Alta Escócia, o fato de a história se passar "ao lado do mar" torna o local tão vago quanto o "era uma vez" e quanto o sobrenome - não mencionado. Esta imprecisão entretanto é contrabalançada pela concretude dos outros elementos espaciais: a caixa em que a cachorrinha fora achada; o local em que fora atropelada; o lugar atrás do fogão em que costumava ficar; a concavidade da rocha na qual o homem a cruzou com outro cachorro; a ilha perto da costa para a qual havia ido quando prenhe, atravessando o mar congelado; o topo da colina na qual é avistada e para o qual ela e os filhotes retornam e depois desaparecem; a praia coberta de cascalhos na qual se dá o reencontro do homem com a cachorra. Todos, entretanto, estão dentro da moldura de "ao lado do mar" e portanto contaminados pela indeterminação não tanto geográfica - o mar na região da Alta Escócia - mas atmosférica - o mar como esta imensidão misteriosa de onde tudo vem e ao qual tudo voltará - reforçada ainda pelo "era uma vez". Por outro lado, os locais nos quais a cachorra continua aparentemente sendo avistada após seu desaparecimento - "aqui e ali ", "num topo de colina numa região", "no cume de outra", "galopando através dos vales e clareiras".8 são todos outra vez geograficamente vagos.

Se esta indeterminação espacial por si só já seria indicio do fantástico, pois "o mistério de onde cla viera" aprofunda "o mistério para onde ela havia ido", 9 ela é ainda seguida de uma indeterminação temporal - "avistada (...) ao amanhecer ou nas sombras do anoitecer. Sempre na área da meia percepção". ${ }^{10}$ Desta maneira, aumenta a ambigüidade do local de sua aparição em termos de

7 "a sort of staghound from another time."

8 "here and there", "on a hill in one region", "on a ridge in another", "loping across the valleys or glens."

9 "the mystery of whence she came"... "the mystery of where she went".

10 "seen(...) in the early morning or the shadowy evening. Always in the area of the half perceived." 
realidade/irrealidade, pois trata-se da hora do crepúsculo, do limiar do dia e da noite e portanto carregada do simbolismo " dessa hora entre dos luces - perigo, medo, escuridão, morte - acrescentando mais um elo ao elemento fantástico já detectado em "de outras eras", com a problematização do real, a vacilação entre uma ilusão visual, o ocultismo e o mitológico.

Mas o espaço cênico ainda inclui, com o desenrolar da história envolvendo os descendentes do homem, o alto rochedo em frente à ilha, no qual o filho mais novo se degola $\mathrm{c}$ cai no mar, após ter visto a cachorra, e uma taverna em Glasgow com passagem de paralelepípedos, onde o outro filho é golpeado até morrer por seis homens grandes e grisalhos. Também esses locais estão impregnados pelo simbolismo do crepúsculo, pois o primeiro acontece ao amanhecer e o segundo na meia penumbra, confirmando assim a área da meia percepção em que eram vistos a cachorra e seus filhotes.

Desta maneira, também a dupla referencialidade do espaço cênico amplo e vago (o mar) ou especifico mas geograficamente vago (ilha, praia, colinas, vales e clareiras) em relação à história do homem e da cachorra, ou mais próximo c específico geograficamente (o rochedo e a taverna $\mathrm{cm}$ Glasgow) em relação à geração seguinte - reforça não só a atmosfera mítica inicial como também, após o incidente, cria uma atmosfera que vai aos poucos se tornando fantástica, pois a cachorra é sempre vista dentro de uma indeterminação temporal, na área da "meia percepção".

Quanto ao foco narrativo, convém ressal tar que o conto se incia com uma narração objetiva, sem a presença ostensiva de um narrador, dentro do "era uma vez", mas que aos poucos vai se tornando subjetiva, isto é, o narrador vai gradativamente deixando nela suas marcas: fazendo referências à própria narrativa - "assim diz a história" 12 - e introduzindo-se na narrativa. Sua primeira intromissão se dả exatamente no momento em que termina de contar a história do homem e da cachorra, ao dizer: “A grande cachorra cinzenta e seus seis filhotes nunca mais foram vistos, ou talvez eu deva dizer-que nunca foram vistos novamente da mesma maneira". ${ }^{3}$ Sua segunda intromissão apresenta o homem como seu antepassado: "O homem grande e bondoso com cheiro de sêmen animal tantas vezes impregnado nas mãos era meu tetravô". ${ }^{14}$ Sua tcrceira intromissão apresenta o homem que foi seu trisavô: -Ele não estava mais

11 Todas as referências simbólicas encontram-se em AD DE VRIES, Dictionary of Symbols and Imagery. Amsterdam, North-Holland, 1974.

12 "as the story goes".

13 "the cui mor glas and her six young dogs were never seen again, or perhaps I should say they were never seen again in the same way."

14 "The large and gentle man with the smell of animal semen often heavy on his hands was my great-great-great-grandfather". 
lá para seu próprio filho da primavera que, por sua vez, tomou-se meu trisavô". ${ }^{15} \mathrm{Na}$ última intromissão, ele termina a história familiar passada e comenta sobre a distância temporal que existe entre os fatos narrados e seu próprio estatuto de narrador: "Foi assim que a grande cachorra cinzenta da morte entrou em nossas vidas e é claro que tudo isso aconteceu há muito, muito tempo". ${ }^{16}$ Esse comentário corre exatamente no momento quando termina a primeira parte da história, pois sua voz vai se tornando cada vez mais individualizante ao se referir aos acontecimentos após a morte do tetravô e a si próprio como descendente do filho mais moço. Assim, da mesma maneira como vai se ampliando a história através das gerações, até chegarmos à própria geração do narrador, também vai se ampliando a subjetividade do mesmo, de "assim diz a história", para "eu deveria dizer", "meu tetravô", "meu trisavô", "em nossas vidas" e este efeito paralelístico novamente demonstra como a narrativa tem uma dupla focalização - de objetiva a subjetiva - reforçando assim a dupla referencialidade do cenário espácio-temporal.

Entretanto, entre esses "dois" pontos de vista, outras intromissōes aparentemente neutras, mas que estāo modalizadas, atravessam a narrativa, dando um toque de hesitação, de ambigüidade e portanto servem de prenúncio ao fantástico - o aparecimento e desaparecimento da cachorra - pois nada é claramente delínido em relação a ela, ficamos sempre no reino da incerteza, da conjetura. Como comenta o narrador, entre outros, "a cù mòr glas e seus seis filhotes (...) nunca foram vistos novamente damesma maneira"; "acreditava-se que a cù mòr glas era avistada aqui e ali"; "houve cada vez mais_especulação acerca da caixa em que fora achada e muita teorização quanto à pessoa ou pessoas que a deixaram lá"; "sentiu-se que ela poderia ter sido parte de feitiçaria"; "mas ninguém conseguia ir muito além disso"; "o que parecia saber-se literalmente era que ela havia atravessado o mar congelado"; "pode-se argumentar que ele morrera por ter sido bom demais"; "alguns dizem que ele viu a grande cachorra cinzenta da morte"; "talvez o homem ouvisse a frase

15 "He was no longer there for his own child of the spring who, in tum, became my great-great-grandfather".

16 "This is how the cì mòr glas a bliais came into our lives, and it is obvius that all of this happened a long, long time ago." 
através de ouvidos"; "onde, muito improvavelmente, supunha-se estarem outros seis homens grandes e de cabelos grisalhos". ${ }^{17}$

É, todavia, quando analisamos as personagens e suas ações, que todo o potencial dos elementos que projetam o fantástico vèm à tona, como constituintes, na realidade, do cerne em torno do qual giram todos os outros acontecimentos posteriores. A frase que se segue à inicial introduz, de maneira quase ingênua, as personagens principais: "E o homem tinha uma cachorra da qual muito gostava". ${ }^{18}$ Se o homem é individualizado adiante apenas como "não era de pequena estatura, tendo um pouco mais de um metro e noventa e pesando talvez noventa quilos", "acostumado a trabalhar com a procriação de animais (...) e muitas vezes com o cheiro forte de sêmen animal em suas mãos grandes e bondosas", 19 portanto tendo como características ser grande, trabalhador e bondoso, é realmente sua cachorra que recebe toda uma carga mitológica e simbólica, a partir de sua descrição: "ela era grande e cinzenta, uma espécie de cão veadeiro de outras eras". ${ }^{20}$

Se os adjetivos "grande e cinzenta" aparentemente marcam uma avaliação não axiológica, o fato de o narrador em seguida se referir a ela como "uma espécie de cão veadeiro de outras cras" nos coloca imediatamente dentro de um discurso modalizante, viabilizando uma avaliação interpretativa. Esta nos remete mais uma vez a um indício do sobrenatural, pois o termo "staghound", simbolizando velocidade e caça, recupera não apenas o mito de Acteon devorado pelos próprios cachorros como o homem punido por intrometer-se em mistérios sccretos, mas também recupera, na mitologia céltica, os cães veadeiros ou galgos que prenunciam a morte. A expressão “de outras eras", como visto, ainda coloca a imagem desse galgo cinzento como vindo de um passado quase primordial, reforçando assim o aspecto sobrenatural e mítico da cachorra.

Seu tamanho é ainda enfatizado por quase derrubar esse homem forte e grande com as patas, pois gostava de saltar e lamber seu rosto para demonstrar

17 "the cù mor glas and her six young dogs (...) were never seen again in the same way"; "the cù mor glas (...) was supposexl to be sighted here and there"; "there was increased speculation about the handmade box in which she had been found and much theorizing as to the individuals or individuals who might have left it"; "it was felt she might have been part of a buidseachd or evil spell"; "but no one could go much farther than that"; "what seemed literally known was that she had crossed the winter ice"; "it may be argued that he died because he was too good"; "some say he saw the cui mòr glas a "bhàis"; "perhaps the man heard the phrase through ears"; "where, most improbably, there were supposed to be six oher large, grey-haired men".

18 "And the man had a dog of which he was very fond."

19 "was not a small man, being slightly over six feet and perhaps one hundred and eighty pounds", "used to working with the breeding of animals (...) and often with the funky smell of animal semen heavy on his large and gentle hands."

20 "she was large and grey, a sort of staghound from another time." 
afetividade, o que o fazia recuar antes de recuperar o equilibrio. Seu tamanho descomunal e cor cinzenta continuam sendo mencionados em diversas ocasiões, como também seus olhos grandes e dentes afiados; esta imagem é até relacionada com a de monstros e seres quase sobrenaturais ou mitológicos, o que confirma ela ter vindo "de outras cras": "por um tempo ela se tornou quase que o Monstro de Loch Ness ou o Sasquatch em escala menor". ${ }^{21}$

Concentrando-nos portanto na "grande cachorra cinzenta", verificamos que o simbolismo do cachorro, ambivalente como todos os grandes simbolos, apresenta características tanto positivas como negativas. Entre seus aspectos positivos, o cachorro é um simbolo feminino, considerado o melhor amigo do homem pelo seu companheirismo, fidelidade, devoção, coragem c proteção, todos aparentes no início da história. O galgo, além de simbolizar velocidade e caça, como visto, ainda simboliza, significativamente, ressurreição pela cor cinza e fertilidade em relação ao pêlo. O fato de a cachorra ter sido deixada, ainda fillhote, no portão da casa da familia, numa pequena caixa feita a mão e ninguém saber de onde viera, acrescenta um ar de mistério à sua origem; isso é reforçado pelo fato de o portão simbolizar, como a porta, uma passagem entre a vida e a morte, e a caixa, conotando segredo, nos remeter também à caixa de Pandora, relacionada com o inesperado e destrutivo. Semelhantemente, o mistério para onde ela teria ido após a morte do homem se torna mais intrigante com as especulações accrca da caixa na qual fora achada $\mathrm{c}$ a pessoa que a deixara na casa do homem, pois a cachorra poderia "ter sido parte de um buidseachd ou feitiçaria lançada no homem por algum misterioso inimigo". ${ }^{22} \mathrm{O}$ uso de uma palavra céltica, significando "feitiçaria", acrescenta agora um toque de fantástico à narrativa, pois "a fantasticidade é, fundamentalmente, um modo de produzir no leitor uma inquietação física (medo e variantes) através de uma inquietação intelectual (dúvida)". ${ }^{23}$ Nossa inquietação gerada pela feitiçaria e nossa vacilação em acreditar que ela ainda esteja viva ou já seja um ser quase mitológico é ainda acentuada por ser comparada a monstros que habitam em águas profundas ou lugares selvagens como os ja citados e por ser, como continua o narrador, "vista mas não registrada. Vista quando não havia máquinas fotográlicas. Vista mas nunca fotografada. ${ }^{24}$

21 "for a while she became rather like the Loch Ness Monster or the Sasquatch on a smaller scale".

22 "she might have been part of a buildseachd or evil spell cast on the man by some mysterious enemy."

23 CHIAMPI, Irlemar. O Realismo Maravilhoso. São Paulo: Perspectiva, 1980. p. 53.

24 "seen but not recorded. Seen when there were no cameras. Seen but never taken." 
Toda essa carga simbólica que a cachorra traz em si, portanto, irá servir de elemento propiciatório para sua transformação de củ mòr glas - a grande cachorra cinzenta - como a chamavam e também m'eudal cù mòr glas - minha grande e querida cachorra cinzenta - como o homem a chama ao seu recncontro na ilha, para cù mòr glas a 'bhàis - a grande cachorra cinzenta da morte - como um dos filhos do homem a chama c como será denominada daquela ocasião $\mathrm{cm}$ diante. Pois se o nome carrega o poder das coisas que representa, o fato de a cachorra não ter recebido nome, mas um aposto, projeta ainda mais a força do simbolismo dos três termos sobre ela - grande, cachorra, cinzenta - e, pelo fato de serem palavras em gaćlico, numa lingua tão desconhecida e misteriosa que até o narrador tem de traduzi-las reforça sua origem misteriosa, como dito. Além disso, a cachorra é a única personagem a receber uma nomeação, o que atesta a potência criadora atribuída à palavra, à nomeação das coisas - a cù mòr glas, emoldurada por mais dois conceitos: amor ( $m^{\prime}$ 'eudal) e morte (d'abhàis). É através dessa caracterização que os três episódios relacionados com o homem e a cachorra se tornam ainda mais significativos, pois se num primciro nível podem ser interpretados como "naturais", eles são enriquecidos pela ambigüidade cênica e temporal, atravessados simultaneamente pelo simbolismo embutido no vulto mitológico da cachorra, desencadcador do clemento fantástico na saga familiar.

Primeiro episódio: é neste episódio, na qual a cachorra, ainda fillhote, é atropelada por uma carroça e o homem lhe salva a vida, que iremos encontrar uma séric de indícios que premunizam o desenvolvimento do fantástico na narrativa e que também encerram motivaçōes semânticas profundas: uma atmosfera outonal e úmida, deixando o solo macio e portanto receptível; a silhueta de seu corpo esmagado na terra depois que o homem a ergueu; scu sangue e urina que mancharam a camisa dele ao erguê-la contra o peito; seus dentes afiados ferindo os dedos dele enquanto a alimentava. Como se vê, há uma dupla contaminação ou batismo: tanto na identificação que ocorreu entre a cachorra, a terra e a chuva - a terra como este grande sepulcro sobre o qual a chuva age como fertilizante - quanto a que ocorreu entre o homem e o sangue, urina e saliva da cachorra, tomando sua amizade ainda mais significativa. Simultaneamente, a convelascença é tornada mais expressiva pela carga simbólica embutida na caixa na qual ela é colocada - forrada com uma camisa velha do homem e com lã de carneiro bem como no fogão atrás do qual a caixa é posta, todos eles relacionados com poderes mágicos de cura.

Segundo episódio: este episódio completa um ciclo no relacionamento da cachorra $\mathrm{e}$ do homem, pois agora temos sua maturação como fêmea, seu envolvimento amoroso com outro cachorro trazido pelo homem, sua prenhez $\mathrm{e}$ 
misterioso desaparecimento. Outros indícios que irão remeter ao fantástico e cuja riqueza simbólica também enfatiza a significação dos eventos são a "tremenda altura", ${ }^{25}$ quase que sobrenatural, da cachorra; a concavidade na rocha, só visível com maré baixa, onde ocorre o cruzamento, com suas conotações de lugar secreto, relacionado com o mundo subterrâneo; c o homem guiando o membro do macho, cujo sêmen permaneceu impregnado em suas mãos, tornando-o assim participante no ritual quase como um segundo macho, como se a cù mòr glas tivesse sido fertilizada não apenas pelo cachorro mas metaforicamente também pelo dono. Assim, da mesma maneira como o homem havia sido contaminado pelo sangue e urina da cachorra após o acidente, agora ele é novamente contaminado pelo sêmen do macho; mais ainda, as mesmas māos que haviam acariciado e cuidado da cachorra são agora responsávcis pela sua impregnação pelo cachorro e assim pela sua futura prenhez. Mesmo assim, por ter participado de um mistério secreto, de um pacto - o cruzamento de animais - cle será mais tarde "punido" de morte pelos fillhotes, recuperando assim o mito de Acteon. Significativamente, um ano após a cù mór glas haver desaparecido enquanto estava prenhe, a esposa do homem também dá à luz a um filho, o décimo segundo, o simbolismo deste número parecendo anunciar que o ciclo vital do homem estava completo, preparando-nos deste modo para o desenlace.

Terceiro episódio: é neste episódio culminante que se colocam os últimos ingredientes fantásticos que irão colorir a narrativa daquí em diante com estranhas coincidências: a tempestade que se aproxima, que força o homem e dois de seus fillhos adolescentes, pescando perto da costa, a se abrigar atrás de uma das ilhas; sua visão da cù mòr glas no alto da colina; e o reencontro do homem com a cachorra, numa cena extremanente chocante e comovente:

M'eudal cù mòr glas gritou o homem em sua felicidade - m'eudal significando algo como querida ou amada; e enquanto gritava, saltou do barco para dentro d'água até a cintura, procurando apoio no cascalho escorregadio enquanto vadeava ansiosa $e$ desajeitadamente em direção dela e da praia. Simultaneamente, a cù mòr glas descia vertiginosamente em direção a ele numa avalanche de pedras soltas pelas suas patas; e bem quando ele emergia d'água, ela o encontrou como costumava, erguendo-se nas patas trazeiras e colocando suas enormes patas dianteiras em seus ombros enquanto estendia a língua ávida.

O impacto c rapidez de seu impeto o pegaram quando ele tentava manter o equilibrio naquele angulo inclinado e no cascalho sob 
seus pés rolando n’água e ele cambaleou para trás, perdeu o apoio e caiu sob a força dela. ${ }^{26}$

Se esta cena nos remete ao inicio do conto, num paralelismo significativo, a história toma agora uma direção imprevisivel e terrivel, pois

naquele momento de novo, como diz a história, apareceram no cume da colina mais seis enormes cachorros cinzentos arremessando-se em direção da praia. Eles nunca haviam visto o homem antes; e vendo-o prostrado sob sua mãe, não compreenderam, como tantas tropas, a intenção de seu líder.

Cairam sobre ele furiosamente, dilacerando seu rosto e rasgando sua mandibula inferior e arrancando seu pescoço, alucinados por sangue ou dever ou talvez fome. ${ }^{27}$

É o mito de Acteon que se repete, estraçalhado c devorado pelos próprios cachorros, pois " $a$ cù mòr glas se virou contra eles em sua própria selvageria, dilacerando e rosnando e, parecia, alucinada pelo erro deles; impelindo-os sangrentos e uivantes à sua frente, de volta ao cume da colina onde desapareceram de vista mas ainda podiam ser ouvidos uivando à distância". ${ }^{28}$

Percebemos aqui todo o simbolismo negativo do cachorro, relacionado com necrofagia, fúria, o demônio, monstro devorador, augúrio de morte. $\mathrm{O}$ simbolismo da colina, relacionada com as colinas mágicas celtas e com o vento,

26 "M'eudal cù mór glas shouted the man in his happiness - m'eudal meaning something like dear or darling; and as he shouted, he jumped over the side of his boat into the waist-deep water, struggling for footing on the rolling gravel as he waded eagerly and awkwandly towards her and the shore. At the same time, the cì mor glas came hurtling down towards him in a shower of small rocks dislodged by her feet; and just as he was emerging from the water, she met him as she used to, rearing up on her hind legs and placing her huge fromt paws on his shoulders while extending her eager tongue.

The weight and speed of her momentum met him as tried to hold his balance on the sloping angle and the water rolling gravel beneath his feet, and he staggered backwards and lost his footing and fell beneath her force."

27 "in that instant again, as the story goes, there appeared over the brow of the hill six more huge grey dogs hurtling down towards the gravelled strand. They had never seen him before; and seeing him stretched prone beneath their mother, they misunderstood, like so many armies, the intention of their leader. They fell upon him in a fury, slashing his face and tearing aside his lower jaw and ripping out his throat, crazed with blood-lust or duty or perhaps starvation."

28 "The cì mòr glas turned on them in her own savagery, slashing and snarling and, it scemed, crazed by their mistake; driving them bloodied and yelping before her, back over the brow of the hill where they vanished from sight but could still be heard screaming in the distance." 
confirma o fato de a cachorra e seus fillhotes habitarem um local mágico com o qual compartilham certas características: os cachorros são tão rápidos como o vento - eles se arremessam colina abaixo c acima; imitam o som do vento pelos uivos que podiam ser ouvidos à distância; c são eternos como o vento - pela sua presença através das gerações seguintes.

Por outro lado, apesar de mutilado e estraçalhado, o pai ainda vive por alguns momentos, enquanto os filhos seguram suas mãos ainda quentes $e$ sangrentas; e, assim como a cù mòr glas quando fillhote o havia contaminado com seu sangue, agora é a vez do pai contaminar os fillhos com seu calor e sangue, novamente como presságio de morte, preparando destarte os acontecimentos ominosos futuros que se tornarão parte da saga familiar.

Se até agora as pinceladas de uma narrativa fantástica foram detectadas quase que aleatoriamente, de agora em diantc elas vão adquirindo cores mais fortes e ameaçadoras; mais importante, teremos uma repetição, com variaçōes, da narrativa mitica. Simultaneamente, esses acontecimentos fantásticos também serão introdutórios à segunda parte da narrativa, que terá lugar no aqui e agora do narrador.

Em termos espácio-temporais temos uma aproximação $\mathrm{cm}$ relação ao narrador, pois os episódios dizem respeito à segunda geração da família e ocorrem no alto do rochedo em frente à ilha e num bar em Glasgow. Em termos de foco narrativo também temos uma aproximação, pois de uma narração objetiva entramos numa narração subjetiva com a presença do narrador. $\mathrm{E}$, em ternos de personagem e ação temos um paralelismo da história do homem em relação aos dois filhos, em cuja memória os episódios da morte do pai permanecem indeléveis - paralelismos esses que projetarão novamente o fantástico na história. Pois a coincidência de um filho ter visto o cachorro em sonhos e cometido suicido num lugar e de modo semelhante à morte do pai e o outro filho imaginar ter visto a cù mòr glas no homem grande e grisalho sentado num bar em Glasgow, e o fato de, durante sua luta com o homem, ele ter sido morto por mais seis homens grandes e grisalhos, confirma o comentário da família de que "a cù mòr glas havia vindo de novo"e também o comentário do narrador que a cachorra e seus seis filhotes nunca haviam sido vistos novamente, -da mesma maneira". 29

Uma nova fase da narrativa se inicia agora, com o narrador comentando "Foi desta maneira que a cù mòr glas a bhàis entrou em nossas vidas, e é natural que tudo isso aconteceu há muito, muito tempo". ${ }^{30}$ Aqui os dois extremos da 
narrativa mítica se unem, o passado familiar com o presente do narrador, que agora nos relata o que aconteceu com as gerações seguintes de sua família, nas quais novamente "parecia que o espectro tinha de alguma maneira vindo para ficar (...) não à maneira de um esqueleto indesejado no armário do passado remoto da familia mas mais à maneira de algo perto de uma possibilidade genética". ${ }^{31}$ A possibilidade genética" parece estar confirmada pelas mortes nas gerações seguintes, quando a cachorra é vista por alguns membros da familia, como: mulheres que deveriam morrer no parto, soldados que foram embora para muitas guerras mas não voltaram e mesmo aqueles que diziam pouco mas diziam a si mesmos "não aconteceu comigo (...) ainda".

Dá-se aqui a grande mudança da narrativa, até agora contada pelo narrador e de agora em diante vivida pelo narrador e portanto saindo do passado mítico para ser relatada no "aqui e agora" do presente. Percebemos novamente uma séric de coincidências que remetem ao passado remoto e também recente da família, que por sua vez anunciam o momento culminante do fantástico - o cventual reencontro com a cù mòr glas d'abhdiis: a ocasião é novamente um outubro chuvoso, como por ocasiāo do primeiro episódio entre o homem e a cachorra. O pai, de cabelos brancos e deitado silenciosamente no meio do branco num leito de hospital em Toronto, está cercado pelo narrador e seus cinco irmãos, deste modo recuperando os seis jovens cachorros da cù mòr glas que haviam matado seu tetravô, bem como os seis homens grandes e grisalhos que haviam matado um dos filhos do homem num bar em Glasgow. Por sua vez, os seis irmãos são todos grisalhos e se revezam ao lado do leito do pai, segurando suas mãos e sentindo sua resposta, como por ocasiāo da morte de seu tetravô, quando os dois filhos seguravam suas mãos sangrentas. E, apesar de ninguém no hospital haver mencionado a cù mòr glas d'abhàis, “é tão difícil não saber o que se sabe", ${ }^{33}$ como costumava dizer a mãe do narrador. Mesmo os mais céticos, como o irmão mais velho, que viera de Montreal, se traem pelos "gestos nervosos". ${ }^{34}$ Simultancamente, como comenta o narrador, "temíamos por ele [o pai moribundo] e por nós. Temíamos o que ele poderia ver e temíamos ouvir a frase nascida da visão". ${ }^{35}$ Como continua, "estamos conscientes de que algumas crenças são o que outros desprezariam como 'besteira'. Estamos

31 "it seemed the spectre had somehow come to stay (...) not in the manner of an unwanted skeleton in the closet from the family's ancient past but more in the manner of something close to a genetic possibility."

32 "it has not happened to me (...) yet".

33 "It is hard to not know what you do know."

34 "nervous actions".

35 "we are afraid for him and for ourselvs. We are afraid of what he may see and we are afraid to hear the phrase born of the vision". 
conscientes de que há homens que acreditam a terra ser plana e os pássaros despertarem o sol". ${ }^{36}$ Em seguida, novamente como numa trilogia ritualistica, o narrador repete:

Presos aqui em nossa própria mortalidade, não desejamos ver ou ver outros verem o que significa a extinção da vida. Não queremos ouvir a voz de nosso pai, como aqueles outros filhos, invocando sua própria morte particular.

Fechariamos os olhos e cobririamos as orelhas, mesmo sabendo tais ações serem inúteis. Atentos ainda e temerosos, os cabelos grisalhos erguendo-se nos pescoços se e quando ouvirmos a luta desordenada das patas e o arranhar na porta. ${ }^{37}$

Assim, apesar de o conto estar dividido nitidamente em duas partes, temos na realidade através da sobreposição de imagens, açōes e falas, uma única narrativa fantástica, com variaçōes sobre o tema central - a saga familiar da grande cachorra cinzenta da morte - que o narrador e seus irmãos accitam, conscientes de que há homens que acreditam "a terra ser plana e os pássaros despertarem o sol". E, se no inicio da narrativa o portão da casa familiar perto do qual fora deixada a cachorrinha se encontra num passado distante, no final da narrativa estamos, como o narrador e seus irmāos, também aguardando ouvir "o debate desordenado das patas e os arranhōes na porta" do quarto do hospital. Simbolizando proteção contra um perigo extemo ou mistério, como a que leva de um estado de ser ao outro, a porta é não apenas a palavra que encerra esta narrativa, num paralelismo que se inicia com o portão da casa familiar. É paradoxalmente também a continuação da história que ainda está para ser contada, pois a fantástica presença da grande cachorra cinzenta da morte vinda "de outras eras" e aguardada do lado de fora da porta, anula toda a temporalidade que separava o tetravô de seus descendentes e do próprio narrador, colocandonos simultaneamente dentro da problematização do real que impregna o conto. Pois agora é a nossa vez de nos deixarmos contaminar pela vacilação entre uma explicação racional dos fatos narrados e uma explicação sobrenatural, cm

36 "we are aware that some beliefs are what others would dismiss as 'garbage'. We are aware that there are men who believe the earth is flat and the birds bring forth the sun."

37 "Bound here in our own peculiar mortality, we do not wish to see or see ohers see that which signifies life's demise. We do not want to hear the voice of our father, as did those other sons, calling down his own particular death upon him. We would shut our eyes and plug our cars, even as we know such actions to be of no avail. Open still and fearful to the grey hair rising on our necks if and when we hear the scrabble of the paws and the scratching at the door." 
decidirmos se também acreditamos na visão da grande cachorra cinzenta, "assim como os pássaros despertam o sol".

\section{RESUMO}

Este trabalho apresenta uma leitura de como as diferentes categorias ficcionais que compõem este conto, tais como o espaço cênico e temporal, o foco narrativo, personagens $\mathrm{e}$ ações, são contaminados pelo fantástico. Deste modo, a força e beleza na saga de cinco gerações de uma familia escocesa são enfatizadas, pois o fantástico faz essas tradições não apenas transcender os limites temporais e geográficos mas também afetar o próprio narrador $\mathrm{e}$ seus irmãos, ao relembrarem "a grande cachorra cinzenta da morte".

Palavras-chave: ficção canadense, Alistair MacLeod, literatura fantástica.

\section{ABSTRACT}

This work presents a reading of how the different fictional categories which comprise this short-story, such as the temporal and spatial setting, characters, point of view and plot, are contaminated by the fantastic. In this way, the power and the fierce beauty in the lore of five generations of a Highland family become foregrounded, as the fantastic makes these traditions not only transcend time and geographical boundaries but also affect the very narrator and his brothers, as they recall their family's "big grey dog of death".

\section{REFERÊNCIAS BIBLIOGRÁFICAS}

CHIAMPI, I. O Realismo Maravillıoso. São Paulo : Perspectiva, 1980.

MACLEOD, A. “As Birds Bring Forth the Sun”. In: BESNER, N. ; STAINES, D. eds.

The Short Story in English. Toronto : Oxford University Press, 1991. VRIES, A. de. Dictionary of Symbols and Imagery. Amsterdam : New Holand, 1974. 